film has, as yet, been investigated, but it is interesting to note that treatment with dilute sulphuric acid, even for a short period, causes ' hard seeds' to behave normally. Prolonged digestion with concentrated caustic potash, on the other hand, has no effect, though normal seeds are reduced to a gelatinous mass in some thirty minutes.

The belief that hardness is not a characteristic of the seed coat, but is due to the deposition of an impermeable film during the last few days of ripening, offers a simple explanation of some facts long known to practical men. For example, 'hard seeds' occur quite promiscuously in any and every consignment, in some more, in others less, the nature of the weather just previous to harvest having a considerable effect on the number. Further, the best ripened seeds always contain most hard seeds.

I hope to proceed further and more critically with the work next summer, but the considerable commercial importance of the subject seems to justify this preliminary note.

Scientific Department,

David Bell, Ltd.,

I7 Coburg Street, Leith, October 26.

\section{The Eggs of the Sucker-fish.}

IN a letter on the eggs of the pilot-fish in NATURE of August I4, I926, p. 228, Mr. K. H. Barnard also mentions the eggs of the sucker-fish (Echeneis naucrates) "which are apparently 'still undescribed." During my researches on the eggs and larvæ of East Indian fishes (cf. Treubia, vol. 2, p. 97 ; vol. 3 , p. 38 ; vol. 5, p. 408 ; vol. 6 , p. 297 ; vol. 8 , p. I99; and vol. 9, p. 389 ), I also became acquainted with the pelagic eggs of the sucker-fish. They are very large, having a diameter of $2.5 \mathrm{~mm}$. The yolk is colourless and fills up the egg membrane fairly well. It contains a small oil globule of a bright yellow colour, diameter I $60 \mu$, and the developing embryo is yellow also, as a consequence of the presence of a large number of yellow pigment spots. Besides these yellow spots there are also black ones, especially on the head and behind the eyes. In due time I hope to give a figure of the egg in Treubia.

I have reared these eggs, isolated from the catches with the surface egg net, several times on board the investigation steamer $D o g$, in glasses with pure seawater. They invariably died, however, after some $2 \frac{1}{2}$ days, about the moment of hatching. I counted 16 + I6 myotomes in an embryo freed artificially from the egg membrane, whereas Echeneis naucrates has $14+16$ vertebræ. My determination is founded chiefly on the examination of a few fresh females with perfectly ripe eggs. These agreed in every respect with the pelagic eggs which I have known for a long time from the Java Sea.

Laboratory for Marine Investigations, Batavia, Java, October 2.

The Symmetrical Top in the Undulatory Mechanics.

By applying the methods of Schrödinger (Ann. $d$. Phys., 79, 361, 489, 734, 1926), which have proved so fruitful in treating atomic problems, to the case of the symmetrical top, we have obtained a complete quantum mechanical solution for this system. The results agree with those found by Dennison (Phys. Rev., 28, 318, 1926) by means of the matrix mechanics ; the energy values are

$$
W_{j n}=\frac{h^{2}}{8 \pi^{2}}\left[\frac{\mathrm{I}}{A_{x}} j(j+\mathrm{I})+\left(\frac{\mathrm{I}}{A_{z}}-\frac{\mathrm{I}}{A_{x}}\right) n^{2}\right],
$$

$A_{x}=A_{y}$ and $A_{z}$ being the moments of inertia of the top.

NO. 2979, VOL. I I 8$]$
The quantum number $j$ and $n$ must have integral values, a result which follows directly from the nature of the characteristic functions, which involve hypergeometric series. This question was not definitely decided by the matrix mechanics, both integral and half-integral values appearing to satisfy the problem. Each value $W_{b n}$ occurs $(2 j+I)$ times as the characteristic value of the system, corresponding to the fact that a state with tnis energy will divide into $2 j+$ I levels under the action of an external field.

Full details will be published elsewhere in the near future.

R. DE L. KRONIG.

I. I. RABI.

Department of Physics, Columbia University, New York, October 26.

\section{Gomplex Aromatic Hydrocarbons in Low- Temperature Tar.}

FROM a tar produced by distillation of Pooley Hall-Wearmouth coal, carbonised at $600^{\circ}$, a fraction boiling at $3^{1} 3^{\circ}-360^{\circ}$ was obtained which yielded a complex mixture of aromatic hydrocarbons distinguished even in an impure state by their bright colours. Predominant among these hydrocarbons is $\beta$-methylanthracene which was identified by conversion into $\beta$-methylanthraquinone and anthraquinone- $\beta$-carboxylic acid. The identity of the $\beta$-methylanthraquinone obtained in our experiments was established by comparison with a specimen of synthetic $\beta$-methylanthraquinone furnished by $\mathrm{Mr}$. W. H. Dawson of the British Alizarine Co. Additional proof of the identity of $\beta$-methylanthracene was obtained by comparing its carboxy acid with the anthraquinone- $\beta$-carboxylic acid prepared by oxidising the $\beta$-methylanthraquinone from the British Alizarine Co.

Investigation of these complex aromatic derivatives from low-temperature tars is being continued in collaboration with H.M. Fuel Research Station.

\section{G. T. MORGAN \\ D. D. Pratt.}

Chemical Research Laboratory,

Teddington, Middlesex.

\section{Welsh Romani.}

As a believer at any rate in the constancy of the law which accords the last word in a discussion to the reviewer, and since the columns of Nature seem scarcely the place for it, I do not propose to deal further here with the novel Romani etymologies propounded by Prof. Turner. The place for this is obviously the Journal of the Gypsy Love Society, of which he is a member, and where scholars who understand Romani and are familiar with what has already been written upon it, will have an opportunity of forming their own opinion. We should then, I presume, learn Prof. Turner's reasons for supposing that *suil could in any dialect of Romani be a possible word, and why a Welsh Gypsy variant of a south European Gypsy word should have a separate origin in a different Indian stem.

The University, Liverpool.

JOHN SAMPSON.

DR. SAMPSON has not replied in any particular to the charge I advanced that in many of his etymologies he had violated the principle of the constancy of the " laws of sound change."

School of Oriental Studies, University of London.
R. L. TURNER. 